\title{
Efektivitas Pembiayaan dan Strategi Pengembangan Usaha Paving Blok di PD Telaga Jaya Blok, Tangerang
}

\author{
Cost-Effectiveness and Business Devolopment Strategy Paving Blok \\ at PD Telaga Jaya Blok, Tangerang
}

\author{
Rohayati $^{1 *}$, H. Musa Hubeis ${ }^{2 \sharp}$, dan Nora H. Pandjaitan ${ }^{3 \sharp}$ \\ ${ }^{1}$ SMA Citra Islami; PS MPI, Sekolah Pascasarjana Institut Pertanian Bogor \\ ${ }^{2}$ Departemen Manajemen, Fakultas Ekonomi dan Manajemen Institut Pertanian Bogor \\ ${ }^{3}$ Departemen Teknik Sipil dan Lingkungan, Fakultas Teknologi Pertanian Institut Pertanian Bogor \\ \#Jl. Kamper Kampus IPB Darmaga, Bogor 16680
}

\begin{abstract}
ABSTRAK
Meningkatnya pembangunan industri memberikan sumbangan positif bagi peningkatan kemakmuran dan kesejahteraan masyarakat dan bangsa Indonesia. Salah satu dari kegiatan industri adalah usaha pembuatan paving blok yang merupakan produk bahan bangunan dari semen yang digunakan sebagai salah satu alternatif penutup atau pengerasan tanah. Tujuan penelitian ini: (1) menganalisis kualitas paving blok berdasarkan Standar Nasional Indonesia (SNI); (2) untuk menganalisis efektivitas biaya produksi paving blok dan (3) merumuskan strategi pengembangan bisnis untuk PD. Telaga Jaya Blok. Penelitian ini menggunakan data primer dan sekunder. Analisis dilakukan dengan menggunakan matriks internal-eksternal (IE), analisis kekuatan, kelemahan, peluang dan ancaman (SWOT atau strengths, weaknesses, opportunities and threats) dan matriks perencanaan strategis kuantitatif (QSPM atau Quantitative Strategic Planning Matrix). Berdasarkan hasil uji laboratorium dari Bina Marga Departemen Tangerang, paving blok, kansteen dan uskup dari PD Telaga Jaya Blok baik, sesuai dengan standar mutu yang ditetapkan di Kabupaten Tangerang dan SNI 03-0691-1996. Analisis profitabilitas standar rasio bahwa PD Telaga Jaya Blok memiliki rasio profitabilitas 35,38\%. Berdasarkan QSPM, prioritas alternatif dapat diurutkan sebagai berikut: (1) meningkatkan loyalitas pelanggan terhadap produk paving block, (2) mempertahankan dan meningkatkan mutu produk, (3) mempertahkan harga jual produk, dan (4) memberikan pelatihan untuk meningkatkan keterampilan karyawan.
\end{abstract}

Kata kunci: efektifitas pembiayaan, paving blok, strategi pengembangan usaha

\begin{abstract}
Increased industrial development make a positive contribution to the increase in prosperity and welfare of the people and the nation of Indonesia. One of the industrial activity is paving block making business which is the product of a cement building materials that are used as an alternative ground cover or hardening. The objectives of this study were: (1) analyze the quality of block paving based on Indonesian National Standard (SNI); (2) to analyze effectiveness of block paving production cost and (3) to formulate business development strategies for PD Telaga Jaya Blok. This study used primary and secondary data. Analysis were done using internal external (IE) matrix, analysis strengths, weaknesses, opportunities and threats (SWOT) and quantitative strategic planning matrix (QSPM). Based on laboratory test results of Bina Marga Department Tangerang, blocks paving, kansteen and uskup of PD. Telaga Jaya Blok were good according to the defined quality standards in Tangerang regency and SNI 03-0691-1996. Analyzes of profitability ratio standard that the PD Telaga Jaya Blok has profitability ratio of $35,38 \%$. Based on QSPM, then alternative priorities can be sorted, as follows : (1) increase customer loyalty to the block paving products, (2) maintain and improve product quality (3) maintain product selling price product and (4) provide training to improve the skills of employees
\end{abstract}

Key words: business development strategies, cost-effectiveness, paving block

*) Korespondensi:

SMA Citra Islami, Jl. Citra Raya Timur No. 1 Ciakar, Panongan Banten 15720; e-mail: yati.munadi@yahoo.co.id 


\section{PENDAHULUAN}

Meningkatnya pembangunan industri memberikan sumbangan positif bagi masyarakat dan bangsa Indonesia. Pembangunan industri bukan hanya untuk membangun pabrik atau peningkatan kapasitas industri, tetapi juga meningkatkan pertumbuhan lapangan kerja, meningkatkan kemakmuran dan kesejahteraan rakyat serta menumbuhkan inisiatif masyarakat dalam pembangunan industri (Hubeis, 2007).

Salah satu dari kegiatan industri adalah usaha pembuatan paving blok yang merupakan salah satu produk bahan bangunan dari semen dan digunakan sebagai salah satu alternatif penutup atau pengerasan tanah. Paving blok disebut juga bata beton (concrete block) atau cone block. Paving blok terbuat dari campuran semen, pasir, batu abu (agregrat halus) dan air dengan atau tanpa tambahan bahan lainnya. Ada berbagai bentuk dan ukuran paving blok yang variasinya tergantung dari pabrik pembuatnya.

Pembangunan yang terus tumbuh di Kabupaten Tangerang, menyebabkan penggunaan paving blok meningkat. Paving blok digunakan untuk pembangunan jalan desa, halaman sekolah dan area umum lainnya. Kemudahan dalam pemasangan dan perawatan yang murah menjadikan paving blok semakin banyak digunakan. Banyaknya kebutuhan pengguna paving blok untuk berbagai konstruksi tidak diimbangi dengan ketersediaan mutu paving yang memadai dari sisi kekuatan, umur pakai dan durability paving itu sendiri (Rommel dan Ninik, 2003). Dinas Pekerjaan Umum di Kabupaten Tangerang telah menetapkan standar paving blok, yaitu K250, K300 dan K350.

Situasi persaingan yang ketat pada industri paving blok terutama di Kabupaten Tangerang, telah memaksa PD Telaga Jaya Blok untuk terus memperbaiki mutu produknya sesuai dengan standar mutu yang ditentukan. Untuk itu kegiatan pengawasan mutu perlu ditingkatkan sehingga jumlah produk yang rusak, atau cacat dari setiap proses produksi dapat dikurangi. Hal ini juga terkait dengan efektivitas penggunaan modal kerja. Jika dihubungkan dengan penjualan, efektivitas yang semakin meningkat akan memungkinkan perusahaan menghasilkan output dengan modal kerja yang relatif lebih sedikit. Semakin tinggi efektivitas penggunaan modal kerja suatu perusahaan, maka akan semakin meningkat profitabilitasnya.
Tujuan kajian ini: (1) Menganalisis kesesuaian mutu paving blok yang dihasilkan PD Telaga Jaya Blok terhadap standar yang berlaku, (2) Menganalisis efektivitas biaya produksi, dan (3) Menyusun strategi pengembangan usaha.

\section{METODE PENELITIAN}

Kegiatan ini dilaksanakan di Perusahaan Dagang (PD) Telaga Jaya Blok yang berlokasi di Jln. Raya Kademangan, Desa Kademangan, Kecamatan Setu, Tangerang Selatan, Banten. Lokasi dipilih dengan pertimbangan bahwa perusahaan sudah beroperasi lebih dari lima tahun dan memiliki jenis produk yang beragam. Kegiatan ini dilakukan dari bulan Maret sampai Agustus 2013.

Data yang digunakan dalam kajian ini adalah data primer dan sekunder yang bersifat kuantitatif dan kualitatif. Pengumpulan data melalui (1) studi kepustakaan (eksplorasi); (2) pengamatan langsung dengan cara mempelajari berbagai dokumen, proses produksi, keuangan dan pemasarannya; (3) membuat daftar pertanyaan (kuesioner) dan wawancara dengan manajemen perusahaan yang terdiri dari pemilik perusahaan, manajer dan bagian produksi PD Telaga Jaya Blok.

Mutu paving blok diuji dengan analisis uji kuat tekan paving blok, yang dilakukan di laboratorium Bina Marga Kabupaten Tangerang. Untuk perhitungan biaya-biaya operasi digunakan analisis Return on Investment (ROI), Return on Common Stockholders'equity atau Return on Equity (ROE) dan Break Event Point (BEP). Selain itu juga dilakukan analisis kuantitatif dengan menggunakan matriks Internal Factor Evaluation (IFE), External Factor Evaluation (EFE), Internal-External (IE) dan Quantitative Strategic Planning Matrix (QSPM).

\section{HASIL DAN PEMBAHASAN}

PD Telaga Jaya Blok didirikan pada tahun 2002, berlokasi di Jalan Kademangan, Desa Kademangan RT 01/03, Tangerang Selatan, Banten. Pada awalnya PD Telaga Jaya Blok hanya memproduksi batako teras. Pada tahun 2005 PD Telaga Jaya Blok mulai memproduksi paving blok karena produk tersebut banyak diminati seiring dengan meningkatnya pembangunan di Kabupaten Tangerang, terutama sebagai salah satu alternatif penutup permukaan tanah, disamping 
paving blok lebih memiliki banyak variasi dari segi bentuk, ukuran, warna, corak dan tekstur permukaan, serta kekuatan. Penggunaan paving blok juga dapat dikombinasikan dengan jenis paving atau bahan bangunan penutup tanah lainnya.

Pada awalnya kapasitas produksi hanya 4.000 buah per hari, dengan berjalannya waktu dan bertambahnya permintaan saat ini kapasitas produksinya perhari mencapai $200 \mathrm{~m}^{2}$ per hari. Jenis produk yang diproduksi PD Telaga Jaya Blok adalah paving blok, kasteen dan uskup. Untuk itu PD Telaga Jaya Blok mulai mengembangkan pabriknya dengan menambah luas areal pabrik, membeli mesin pencetak paving blok hidrolik dan menambah sarana transportasi.

Material yang digunakan dalam pembuatan paving blok adalah semen portland, abu batu, air dan pasir. Tahapan proses produksi paving blok yang dilakukan (1) Siapkan komposisi bahan pertama, yaitu abu batu, semen dan air serta adukan bahan kedua berupa pasir, semen dan air, (2) masukan masing-masing bahan ke dalam ke dalam mesin pengaduk yang berbeda, (3) tuangkan bahan pertama ke dalam pencetak dengan ketebalan kurang lebih $5 \mathrm{~cm}$ (untuk paving blok dengan ketebalan $6 \mathrm{~cm}$ ), (4) tuangkan bahan kedua di atas bahan pertama dan ratakan (5) cetak dengan kekuatan tertentu (6) keluarkan dari pencetak dan (7) keringkan paving block mentah dengan cara diangin-anginkan atau di jemur di bawah terik matahari sehingga didapat paving block yang matang. Kuat aus pada lapisan atas lebih dipengaruhi oleh variasi pressing, semakin besar pressing yang diberikan maka didapat kuat aus paving yang semakin kecil (Rommel, 2011).

Perusahaan memiliki bangunan produksi, kantor, gudang dan lahan untuk menjemur/ mengeringkan paving blok, seluas $8.500 \mathrm{~m}^{2}$. Peralatan produksi yang dimiliki adalah mesin press paving blok hidrolik dan mesin getar. Bahan baku paving blok diperoleh dari beberapa tempat, abu batu dari Desa Rumpin di Bogor dan pasir bangka dipesan langsung dari Pulau Bangka. Semen SNI tipe 1.

\section{Analisis Aspek Mutu}

PD Telaga Jaya blok secara kontinyu menguji mutu produknya di laboratorium Bina Marga Tangerang. Dari hasil uji tekan terhadap 15 buah contoh paving blok didapatkan bahwa produksi PD Telaga Jaya Blok sesuai standar yang telah ditetapkan di Kabupaten Tangerang.

\section{Analisis Efektivitas Pembiayaan}

Efektivitas pembiayaan dianalisis dari profitabilitas perusahaan. Jika perusahaan berhasil meningkatkan profitabilitasnya, maka dinilai mampu mengelola sumber daya yang dimilikinya secara efektif dan efisien, sehingga mampu menghasilkan laba yang tinggi. Berdasarkan hasil analisis rasio profitabilitas diperoleh bahwa PD Telaga Jaya Blok memiliki rasio GPM (gross profit margin) yang cenderung meningkat pada tahun 2011-2012. Pada tahun 2011 diperoleh GPM $34,73 \%$ dan meningkat menjadi $35,38 \%$ pada tahun 2012. Hal ini berarti untuk setiap Rp1 penjualan yang dilakukan perusahaan memperoleh laba Rp0,3538. Hal tersebut disebabkan karena terdapat penurunan HPP dan biaya operasional perusahaan. Rekapitulasi rasio profitabilitas PD Telaga Jaya Blok dapat dilihat pada Gambar 1.

Laba operasional sebelum bunga dan pajak yang dihasilkan oleh setiap rupiah penjualan mengalami peningkatan pada tahun 2011 diperoleh $19,36 \%$ menjadi $20,92 \%$ pada tahun 2012 . Hal ini berarti setiap Rp1 penjualan yang dilakukan perusahaan memperoleh laba operasional Rp0,2029. Hal ini disebabkan menurunnya nilai aktiva tetap pada tahun 2012. Keuntungan bersih yang diperoleh perusahaan dari setiap rupiah penjualan mengalami penurunan dari 10,85\% menjadi $10,61 \%$, sebagai akibat meningkatnya biaya di luar biaya operasional pada tahun 2012 .

Tingkat pengembalian dari bisnis atas seluruh investasi yang dilakukan atau ROI fluktuatif, dan pada tahun 2012 mencapai 30,39\%. Hal ini menunjukkan bahwa atas setiap investasi Rp1 perusahaan memperoleh laba Rp0,3039. Tingkat pengembalian modal atau ROE cenderung stabil dan pada tahun 2012 mencapai 15,35\% yang berada di atas rataan industri $14,15 \%$. Hal ini menunjukkan bahwa setiap Rp1 investasi, perusahaan memperoleh tingkat pengembalian 15,35\% atau $\mathrm{Rp} 0,1535$. Secara umum, perusahaan memiliki rasio profitabilitas yang cukup sehat dan baik.

\section{Analisis Strategik}

Matriks EFE disusun berdasarkan identifikasi terhadap faktor-faktor internal perusahaan berupa kekuatan (strengths) dan kelemahan (weaknesses) yang berpengaruh terhadap pengembangan usaha paving blok. Dengan memasukkan hasil identifikasi kekuatan dan kelemahan sebagai faktor strategik internal, maka diperoleh hasil seperti terlihat pada Tabel 1. 


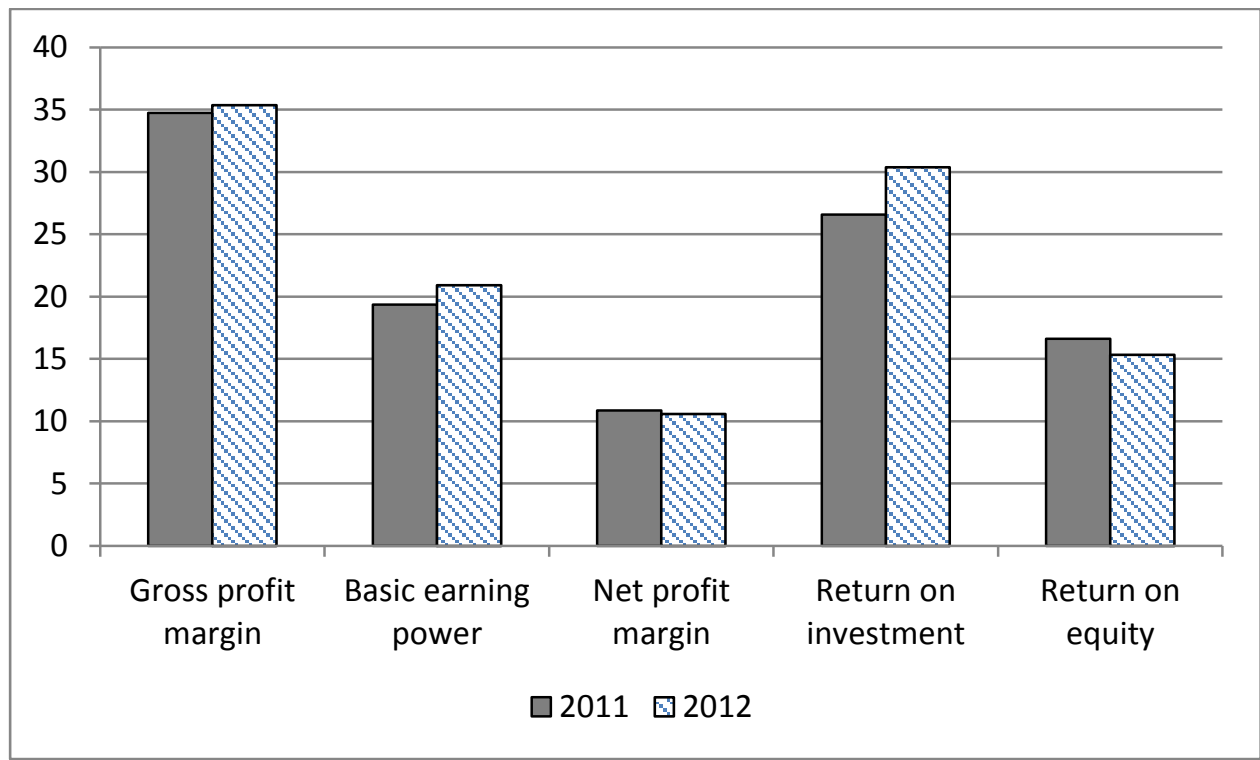

Gambar 1. Rekapitulasi rasio profitabilitas PD Telaga Jaya Blok

Tabel 1. Faktor strategik internal PD Telaga Jaya Blok Tahun 2013

\begin{tabular}{|c|c|c|c|c|}
\hline Faktor Strategik Internal & $\begin{array}{c}\text { Bobot } \\
\text { (a) }\end{array}$ & $\begin{array}{l}\text { Rating } \\
\text { (b) }\end{array}$ & $\begin{array}{c}\text { Skor } \\
\left(\mathrm{c}=\mathrm{a}^{*} \mathrm{~b}\right)\end{array}$ & $\begin{array}{l}\text { Ranking } \\
\text { (d) }\end{array}$ \\
\hline \multicolumn{5}{|l|}{ A. Kekuatan } \\
\hline Lokasi perusahaan strategis & 0,113 & 3,67 & 0,415 & 5 \\
\hline Lokasi usaha milik sendiri & 0,103 & 3,00 & 0,309 & 1 \\
\hline Modal sendiri & 0,094 & 3,67 & 0,345 & 4 \\
\hline Bahan baku diambil sendiri & 0,083 & 3,67 & 0,305 & 2 \\
\hline Transportasi milik sendiri & 0,107 & 3,00 & 0,321 & 3 \\
\hline Jumlah A & 0,500 & & 1,695 & \\
\hline \multicolumn{5}{|l|}{ B. Kelemahan } \\
\hline Keterbatasan modal & 0,093 & 2,00 & 0,186 & 5 \\
\hline Disiplin pegawai rendah & 0,087 & 1,67 & 0,145 & 2 \\
\hline Manajer kurang terampil & 0,117 & 1,33 & 0,156 & 3 \\
\hline Keterampilan pegawai rendah & 0,094 & 1,33 & 0,125 & 1 \\
\hline Tidak ada bagian quality control & 0,109 & 1,67 & 0,182 & 4 \\
\hline Jumlah B & 0,500 & & 0,794 & \\
\hline Total $(\mathrm{A}+\mathrm{B})$ & 1,000 & & 2,489 & \\
\hline
\end{tabular}

Tabel 2. Faktor strategik eksternal PD Telaga Jaya Blok Tahun 2013

\begin{tabular}{|c|c|c|c|c|}
\hline Faktor Strategik Eksternal & $\begin{array}{c}\text { Bobot } \\
\text { (a) }\end{array}$ & $\begin{array}{l}\text { Rating } \\
\text { (b) }\end{array}$ & $\begin{array}{c}\text { Skor } \\
\left(\mathrm{c}=\mathrm{a}^{*} \mathrm{~b}\right)\end{array}$ & $\begin{array}{l}\text { Ranking } \\
\text { (d) }\end{array}$ \\
\hline \multicolumn{5}{|l|}{ A. Peluang } \\
\hline Meningkatnya permintaan paving blok & 0,119 & 4,00 & 0,476 & 5 \\
\hline Hubungan baik dengan pemasok & 0,104 & 3,00 & 0,311 & 3 \\
\hline Adanya pelanggan tetap & 0,102 & 3,00 & 0,360 & 2 \\
\hline Adanya penawaran kerjasama & 0,098 & 3,67 & 0,360 & 4 \\
\hline Lokasi bahan baku dekat & 0,100 & 3,00 & 0,300 & 1 \\
\hline Jumlah A & 0,523 & & 0,754 & \\
\hline \multicolumn{5}{|l|}{ B. Ancaman } \\
\hline Perkembangan model paving blok & 0,096 & 1,00 & 0,096 & 1 \\
\hline Fluktuatif harga bahan baku & 0,093 & 2,00 & 0,185 & 5 \\
\hline Pembajakan pegawai & 0,081 & 1,67 & 0,135 & 3 \\
\hline Jalan menuju lokasi sempit & 0,096 & 1,33 & 0,128 & 2 \\
\hline Adanya kenaikan BBM & 0,111 & 1,33 & 0,148 & 4 \\
\hline Jumlah B & 0,477 & & 0,693 & \\
\hline Total $(\mathrm{A}+\mathrm{B})$ & 1,000 & & 2,447 & \\
\hline
\end{tabular}


Matriks EFE disusun berdasarkan identifikasi terhadap faktor-faktor eksternal perusahaan berupa peluang (opportunities) dan ancaman (threats) yang berpengaruh terhadap pengembangan usaha paving blok. Dengan memasukkan hasil identifikasi peluang dan ancaman sebagai faktor strategik, maka diperoleh hasil seperti terlihat pada Tabel 2.

Pemetaan posisi perusahaan sangat penting bagi pemilihan alternatif strategi dalam menghadapi persaingan dan perubahan yang terjadi dalam industri paving blok. Dengan total nilai pada matriks internal 2,489, maka perusahaan memiliki faktor internal tergolong sedang atau rataan dalam melakukan industri paving blok. Total nilai matriks eksternal 2,447 memperlihatkan respon yang diberikan oleh PD Telaga Jaya Blok kepada lingkungan eksternal tergolong sedang. Posisi perusahaan pada Matriks IE dapat dilihat pada Gambar 2.

Pada matriks IE tersebut nilai yang diperoleh berada pada kotak kuadran $\mathrm{V}$, yaitu hold and maintain atau pertahankan dan pelihara (David, 2004). Strategi yang disarankan untuk diterapkan pada kondisi tersebut adalah strategi penetrasi pasar dan pengembangan produk. Dalam hal ini, PD Telaga Jaya Blok menerapkan strategi pemasaran untuk melakukan penetrasi pasar dengan tujuan menembus wilayah pasar yang belum dikuasai, yaitu membuka atau bekerjasama dengan toko bangunan atau outlet baru dan kontraktor.

Secara nasional tidak tersedia data mengenai besarnya permintaan untuk produk paving blok. Dilihat dari penggunanya, paving banyak digunakan untuk keperluan penutupan tanah seperti trotoar jalan, halaman rumah, halaman kantor, swalayan dan supermarket, areal parkir, areal penumpukan peti kemas di pelabuhan, areal taman, garasi, jalan desa dan jalan-jalan di komplek perumahan. Strategi berikutnya melakukan pengembangan produk dengan mutu produk secara bertahap dikembangkan melalui pengawasan bahan baku, proses produksi dan pasca produksi. Jika modal dan jumlah produksi sudah bertambah dalam jumlah besar, diharapkan perusahaan dapat mempertimbangkan penggunaan teknologi yang lebih maju untuk meningkatkan kapasitas produksi dan mutu produk. Sesuai penelitian Sebayang et al (2011), bahwa mutu kuat tekan yang dihasilkan oleh industri mesin lebih stabil nilai kuat tekannya dibandingkan dengan buatan industri manual untuk setiap hasil cetakan yang dibuat. Terkait dengan penggunaan teknologi, metode pemadatan dengan cara vibrating menghasilkan kuat tekan paving yang lebih rendah dibandingkan memakai cara pressing (Rommel, 2009). Kuat tekan paving blok akan mencapai maksimum pada penggantian semen dengan abu batubara sebanyak 30\% (Sutarno dan Sukardi, 2008).

\section{Analisis Matriks SWOT}

Setelah mengetahui posisi perusahaan saat ini dan diperoleh inti strategi perusahaan, maka selanjutnya menyusun faktor-faktor strategi bagi perusahaan dengan menggunakan matriks SWOT (Rangkuti, 2008). Matriks SWOT PD Telaga Jaya Blok Tahun 2013, dapat dilihat pada Gambar 3.

Total Skor Evaluasi Faktor Internal

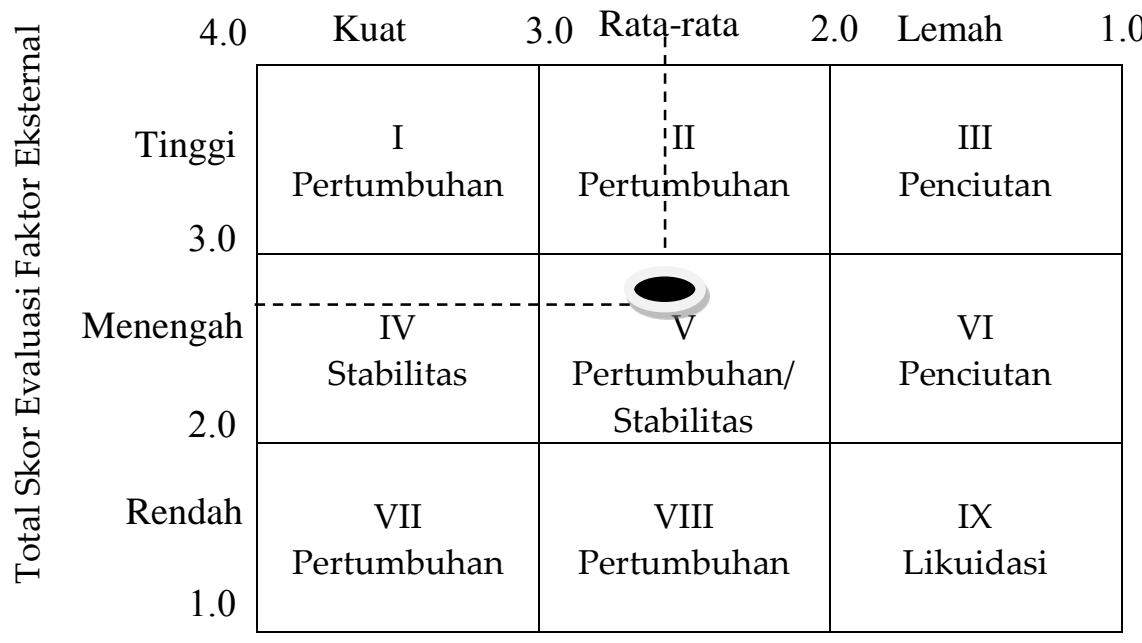

Gambar 2. Matriks IE industri paving blok PD Telaga Jaya Blok 


\begin{tabular}{|c|c|c|}
\hline EKSTERNAL & $\begin{array}{l}\text { STRENGTH - S } \\
\text { S1. Lokasi perusahaan strategis } \\
\text { S2. Lokasi usaha milik sendiri } \\
\text { S3. Modal sendiri } \\
\text { S4. Bahan baku diambil sendiri } \\
\text { S5. Transportasi milik sendiri }\end{array}$ & $\begin{array}{l}\text { WEAKNESSES - W } \\
\text { W1. Keterbatasan modal } \\
\text { W2. Disiplin pegawai rendah } \\
\text { W3. Manajer kurang terampil } \\
\text { W4. Keterampilan pegawai rendah } \\
\text { W5. Tidak ada quality control }\end{array}$ \\
\hline $\begin{array}{l}\text { OPPORTUNITIES - O } \\
\text { O1. Meningkatnya permintaan } \\
\text { paving blok } \\
\text { O2. Hubungan baik dengan } \\
\text { pemasok } \\
\text { O3. Adanya pelanggan tetap } \\
\text { O4. Adanya penawaran kerjasama } \\
\text { O5. Lokasi bahan baku dekat }\end{array}$ & $\begin{array}{l}\text { STRATEGI S - O } \\
\text { 1. Mempertahankan dan memper- } \\
\text { luas jaringan pemasaran } \\
\text { (O1,O2,O3,S1,S3,S5) } \\
\text { 2. Memelihara dan mempertahankan } \\
\text { mutu produk (O2,O4, O5,S1,S2,S4) } \\
\text { 3. Mengembangkan jejaring dengan } \\
\text { perusahaan sejenis, baik skala } \\
\text { yang sama atau lebih besar } \\
\text { (O1,O2,O3,S1,S2,S4) }\end{array}$ & $\begin{array}{l}\text { STRATEGI } \mathbf{W}-\mathrm{O} \\
\text { 1. Melakukan promosi dengan } \\
\text { efektif dan efisien }(\mathrm{O} 2, \mathrm{O} 3 \text {, } \\
\text { O5,W2,W3) } \\
\text { 2. Meningkatkan kinerja pegawai } \\
\text { (O1,O3,O4,W2,W4) } \\
\text { 3. Menjalin hubungan dengan } \\
\text { pemasok melalui pola sub } \\
\text { kontrak (O1,O2,O4,W1,W5) }\end{array}$ \\
\hline $\begin{array}{l}\text { THREATS - T } \\
\text { T1. Perkembangan model paving } \\
\quad \text { blok } \\
\text { T2. Fluktuatif harga bahan baku } \\
\text { T3. Pembajakan pegawai } \\
\text { T4. Jalan menuju lokasi sempit } \\
\text { T5. Adanya kenaikan BBM }\end{array}$ & $\begin{array}{l}\text { STRATEGI S - T } \\
\text { 1. Meningkatkan kepercayaan } \\
\text { konsumen terhadap produk paving } \\
\text { blok (T1,T3,T4,S2,S3,S5) } \\
\text { 2. Melakukan efisiensi untuk } \\
\text { menekan biaya produksi } \\
\text { (T1,T2,T5,S4,S5) }\end{array}$ & $\begin{array}{l}\text { STRATEGI } \mathbf{W}-\mathbf{T} \\
\text { 1. } \\
\text { Mempertahankan harga jual } \\
\text { produk dengan meningkatkan } \\
\text { pelayanan (T1,T2,T3,T4, W3,W5) } \\
\text { 2. Mengembangkan produk } \\
\text { alternatif (T2,W4,W5) }\end{array}$ \\
\hline
\end{tabular}

Gambar 3. Perumusan strategi PD Telaga Jaya Blok dengan matriks SWOT

Untuk pengambilan keputusan menentukan prioritas strategi yang paling tepat dilaksanakan, maka dilakukan analisis matriks QSPM. Pembobotan pada masing-masing faktor internal dan eksternal yang digunakan sama dengan bobot yang digunakan pada matriks IFE dan EFE. untuk penilaian Attractiveness Score (AS) didapatkan dari hasil kuesioner terhadap tiga orang nara sumber yang terdiri dari Pemilik, Manajer dan Kepala Bagian Produksi. Nilai yang diambil merupakan rataan dari penilaian ketiga nara sumber tersebut, yang selanjutnya menghasilkan nilai Total Attractiveness Score (TAS).

Berdasarkan hasil analisis QSPM, strategi terbaik yang harus dilakukan dengan nilai TAS tertinggi $(5,640)$ adalah mempertahankan harga jual produk di pasaran dengan tujuan agar pelanggan terhadap produk paving blok, khususnya pelanggan kontraktor dan Dinas Bina Marga Kabupaten Tangerang tetap membeli produk PD Telaga Jaya Blok. Harga jual produk merupakan salah satu daya tarik konsumen, terutama para kontraktor dalam membeli produk, kontraktor berharap untuk mendapat harga lebih murah tanpa mempertimbangkan mutu produk. PD Telaga Jaya Blok berusaha menjaga harga jual produknya dengan tetap mempertimbangkan mutu dari produknya. Strategi tersebut dapat dilakukan dalam empat program, yaitu: a. Program pemasaran, terutama dengan mempertahankan harga jual produk di pasaran, meningkatkan kepercayaan konsumen terhadap produk paving blok, mempertahankan dan memperluas jaringan pemasaran serta melakukan promosi dengan efektif dan efisien.

b. Program pengembangan SDM, dengan meningkatkan kinerja pegawai.

c. Program kemitraan, terutama dengan menjalin hubungan dengan pemasok melalui pola sub kontrak serta mengembangkan jejaring dengan perusahaan sejenis, baik skala sama atau lebih besar.

d. Program produksi, dengan mempertahankan mutu produk, melakukan efisiensi untuk menekan biaya produksi dan melakukan alternatif produk.

\section{Implikasi Manajerial}

Paving blok merupakan alternatif material penutup permukaan bangunan untuk pengganti aspal, maka paving blok dapat dibentuk untuk menghasilkan efek menarik, fitur unik, rapi dan mempunyai daya tahan cukup kuat. Saat ini paving blok bahkan digunakan di daerah-daerah beban berat, seperti pelataran parkir, dermaga dan jalan umum, karena memiliki keunggulan, cukup banyak dibandingkan dengan material penutup permukaan bangunan lainnya. 
Tabel 4. Indikator, kebutuhan, tindakan dan waktu pelaksanaan

\begin{tabular}{|c|c|c|c|}
\hline Indikator Prioritas & Kebutuhan (Need) & Tindakan (Action) & $\begin{array}{c}\text { Waktu } \\
\text { Pelaksanaan }\end{array}$ \\
\hline $\begin{array}{l}\text { Mempertahankan harga } \\
\text { jual produk }\end{array}$ & $\begin{array}{l}\text { - Menjaga mutu } \\
\text { - Bahan baku kontinu } \\
\text { - Produktifitas kerja }\end{array}$ & $\begin{array}{l}\text { - Kontrak kerja dengan bagian } \\
\text { produksi } \\
\text { - Kontrak kerja dengan pemasok }\end{array}$ & Jangka pendek \\
\hline $\begin{array}{l}\text { Meningkatkan kinerja } \\
\text { SDM }\end{array}$ & $\begin{array}{l}\text { - Kedisiplinan pegawai } \\
\text { - Keterampilan pegawai }\end{array}$ & $\begin{array}{l}\text { - Komitmen pegawai } \\
\text { - Training pegawai }\end{array}$ & Jangka pendek \\
\hline Pola sub kontrak & Kesinambungan usaha & $\begin{array}{l}\text { Kemitraan dengan pemasok bahan } \\
\text { baku }\end{array}$ & Jangka pendek \\
\hline $\begin{array}{l}\text { Memelihara dan } \\
\text { mempertahankan mutu } \\
\text { produk }\end{array}$ & $\begin{array}{l}\text { - Bahan baku kontinu } \\
\text { - Mutu produk }\end{array}$ & $\begin{array}{l}\text { - Kontrak kerja dengan pemasok } \\
\text { - Pelatihan pegawai }\end{array}$ & Jangka pendek \\
\hline
\end{tabular}

Strategi yang dikembangkan dapat dikelompokkan atas program pemasaran, program produksi, program SDM dan program kemitraan. Beberapa implikasi manajerial dapat digunakan oleh manajemen dalam menetapkan strategi pengembangan paving blok. Implikasi-implikasi manajerial tersebut disajikan pada Tabel 4.

\section{KESIMPULAN}

1. PD Telaga Jaya Blok memproduksi paving blok, kanstin dan uskup yang sesuai standar mutu yang ditetapkan di Kabupaten Tangerang dan SNI 03-0691-1996, yaitu paving blok mutu beton kelas D atau C.

2. Perusahaan memiliki rasio profitabilitas cukup sehat dan baik, ditunjukkan dari kriteria perolehan laba dalam hubungannya dengan penjualan, total aktiva maupun modal sendiri.

3. Hasil analisis SWOT yang dilanjutkan dengan QSPM, menghasilkan prioritas alternatif yang dapat dikelompokkan atas program pemasaran, pengembangan SDM, kemitraan dan produksi.

\section{DAFTAR PUSTAKA}

David, F. R. 2004. Manajemen Strategis. PT. Indeks Kelompok Gramedia, Jakarta.

Hubeis, M. 2007. Dasar-Dasar Manajemen Industri. Inti Prima, Jakarta.

Rangkuti F. 2008. Analisis SWOT Teknik Membedah Kasus Bisnis. Gramedia Pustaka Utama, Jakarta.

Rommel, E. 2011. Pemakaian Fine Coarse Aggregate Sebagai Bahan Paving Tahan Aus. Media Teknik Sipil, 9 (1): 29-35.

Rommel, E. 2009. Teknologi Pembuatan Paving Block dengan Material FCA (Fine Coarse Aggregate). Jurnal GAMMA, IV (2): 110-116.

Rommel E, dan Ninik CEY. 2003. Teknologi Pembuatan dan Pola Pemasangan Paving untuk Mengoptimalkan Kualitas Paving Block. Prosiding Simposium Nasional II RAPI, UMS, Surakarta, ISSN 1412-9612.

Sebayang S, Diana IW, Purba A. 2011. Perbandingan Mutu Paving Block Produksi Manual dengan Produksi Masinal. Jurnal Rekayasa, 15 (2): 139-150.

Sutarno dan Sukardi. 2008. Peningkatan Kuat Tekan Paving Blok Dengan Memanfaatkan Abu Batu Bara Limbah Industri. Wahana Teknik Sipil, 13 (3): 186-196. 